\title{
A abordagem CTS-Arte nos estudos das estações de tratamento de esgoto: uma prática no ensino fundamental
}

\section{The STS-Art approach in studies of sewage treatment plants: a practice in elementary education}

\author{
${ }^{1}$ Samara de Almeida Andrade \\ ${ }^{2}$ Roberto Dalmo Varallo Lima de Oliveira \\ ${ }^{3}$ Glória Regina Pessôa Campello Queiroz \\ ${ }^{1}$ Willian Zamboni de Mello
}

\section{RESUMO}

O tema "Estações de Tratamento de Esgoto" é de extrema relevância quando se busca a formação de cidadãos com capacidade de interpretar e criticar o meio que está inserido. Com intuito de estabelecer uma formação mais crítica, que aproxime as áreas exatas das áreas humanas e de ampliar a compreensão do outro, o presente trabalho busca a aproximação da Arte com a Educação em Química e, para isso, utiliza como referencial teórico a estratégia didática CTS- ARTE (Ciência, Tecnologia e Sociedade). O trabalho é desenvolvido em duas principais etapas: 1) Elaboração e aplicação das aulas; 2) Elaboração da pesquisa, que consiste em analisar o conteúdo da arte desenvolvida pelos alunos, cujo principal objetivo é encontrar as relações diretas e indiretas com todas as fases do trabalho, sendo essas: literatura de cordel, ETE (Estação de tratamento de esgoto), conteúdo científico de separação de mistura, o momento político que a cidade estava vivendo. Os alunos, em sua maioria, tiveram falas que expuseram nas suas artes todos os outros temas como a política, ou seja, a falta da mesma na cidade onde residem.

Palavras-Chave: CTS - ARTE, Educação em química, Ensino Fundamental.

\section{ABSTRACT}

The theme "Sewage Treatment Plants" is extremely important when seeking the formation of citizens with the ability to interpret and criticize the way it is inserted. With intuited to establish a training more critical, which approximates the exact areas of the humanities and expand the understanding of the other, this paper seeks the approximation of Arts with Education in Chemistry and, therefore, used as a theoretical strategy didactic CTS - ART (Science, Technology, and Society). The work is carried out in two main steps: 1. Development and implementation of classes 2. Preparation of research. Where the stage of the research is to analyze the content of art developed by students. Where the main goal was to find the artwork of students the direct and indirect relations with all phases developed during the work, these being: string literature, STP (sewage treatment plant), scientific content separation mixture, the political moment that the town was living. The students mostly had their speeches that exposed the arts all other issues with the policy, or the lack of it in the city where they reside.

Keywords: STS-ART, Chemistry Education, Elementar Education

1 Universidade Federal Fluminense (UFF)

2 Centro Federal de Educação Tecnológica Celso Sukow da Fonseca (CEFET-RJ) / Universidade Federal do Tocantins (UFT) - Campus Araguaína

3 Universidade do Estado do Rio de Janeiro (UERJ) 


\section{INTRODUÇÃO}

O presente trabalho é uma pesquisa realizada a partir da confluência entre a Educação em Artes e a Educação em Química. Dois campos aparentemente separados, mas aproximados pela estratégia didática chamada CTS-ARTE apresentada por Oliveira e Queiroz (2013). A princípio, trabalharemos alguns conceitos da abordagem CTS-ARTE (Ciência, Tecnologia e Sociedade) e mostraremos alguns dos motivos para a escolha da obra de arte usada e algumas de suas possibilidades didáticas. A elaboração da aula a partir da estratégia didática CTS-ARTE nos levou a questionar "como os estudantes, através da Arte Final, expressaram as discussões de cada uma das aulas envolvidas na estratégia?” e, para responder a essa pergunta, utilizaremos a análise de conteúdo (MORAES, 1999).

\section{A abordagem CTS-ARTE}

Uma das ideias que está sendo difundida há alguns anos na área de pesquisa em Educação em Ciências é a necessidade de uma formação básica para que os estudantes consigam compreender uma dimensão social da Ciência e sua relação com a tecnologia e a sociedade, sendo capazes de refletir de maneira crítica, elaborando juízos de valor até mesmo sobre práticas científico-tecnológicas (BRASIL, 1998). Essa "forma de pensar" a educação científica está presente em um grande movimento internacional que se chama Ciência, Tecnologia e Sociedade (CTS).

Acevedo-Dias, Vasquez-Alonso e Manassero-Mas (2005) afirmam que um dos fatores primordiais que resultou no surgimento do CTS foi o lançamento das bombas de Hiroshima e Nagasaki. Outros fatores que colaboraram para o movimento CTS foram os diversos movimentos sociais, como o ambientalista e o feminista (AIKENHEAD, 2005). Esses diversos fatores contribuíram para que houvesse o questionamento sobre um modelo linear, proposto por Bush (1945), no qual se estabelecia a proporcionalidade entre desenvolvimento cientifico e social, acarretando num desenvolvimento tecnológico estreitamente relacionado ao desenvolvimento social. No que se refere ao ensino, alguns dos principais fatores para o surgimento da abordagem CTS foram: o movimento de reformas curriculares no ensino de ciências e a insistência de educadores por apresentar uma concepção mais humana dessas disciplinas, o que fez com que o movimento CTS gerasse mudanças no status quo da educação científica (AIKENHEAD, 2005).

Diversos projetos em todo o mundo foram feitos utilizando uma concepção de CTS, de forma que é possível encontrar vários sentidos dentro dessa área. Aikenhead propôs um espectro que expressa a importância relativa de conteúdos CTS de acordo com a estrutura do conteúdo (conteúdo científico tradicional ou CTS) e a sua avaliação (de acordo com a importância na compreensão do conteúdo científico versus a compreensão do conteúdo CTS). Foram separadas oito categorias em um continuum que vai gradualmente incorporando elementos CTS aos currículos, sendo que a 1) apresenta um conteúdo tradicional com algumas noções de CTS e a 8) apresenta uma alta prioridade de conteúdos CTS e uma baixa prioridade aos conteúdos científicos. Independente da localização do tipo de abordagem dentre o espectro apresentado por esse autor, há uma busca pela capacidade na tomada de decisão para uma ação social responsável, ou seja, considerando os valores e as questões éticas. Entretanto, Auler (2007) faz uma ressalva e mostra que a abordagem CTS, apesar de possuir diversos sentidos e práticas, tem sido utilizada em maior escala apenas como uma motivação para 'cumprir o programa' e 'vencer conteúdos’.

Segundo Oliveira e Queiroz (2013) a educação CTS deve contribuir para a formação de cidadãos capazes de compreender relações que envolvam Ciência, Tecnologia e Sociedade associando aos conteúdos científicos curriculares. Preparando-os para pesquisar e participar de estudos que sejam relevantes ao longo de sua vida, para o seu crescimento intelectual. Desenvolver senso crítico ao ponto de desconfiarem de verdades impostas, tomarem decisões coerentes respeitando as diversidades em todas as formas de expressão. 


\section{A aproximação com a Arte}

Uma prática que valorize a diversidade cultural em aulas de Ciências deverá caminhar na superação de duas questões. A primeira, apresentada por Snow em 1959, que cita a existência de uma aparente oposição entre a cultura cientifica e a cultura humanística. Já a segunda, apresentada pela professora Vera Candau (2010), nos leva a criticar a educação homogeneizadora e monocultural. Nas palavras da autora, deve-se considerar a escola como uma instituição no centro do cruzamento de diferentes culturas, onde é necessário promover o dialogo cultural.

A abordagem intercultural em Artes é considerada benéfica por Richter (2010), uma vez que consegue envolver conceitos como cultura, identidade cultural, alteridade, universalidade e regionalismo, as igualdades e as diferenças, relativizando as situações de poder e contrastando com verdades estabelecidas. As Artes possibilitam envolver temas como sexualidade, racismo, inclusão, identidades juvenis, de periferia, de grupos religiosos etc. Outro ponto é destacado por Ranciére (2005) ao afirmar que “A Arte sempre faz política” e que a estética é atravessada por um projeto de Arte que é transcendida.

No intuito de agregar esses diversos fatores, como a aproximação da cultura científica e humanística, a compreensão da Ciência como uma construção humana e social, ou seja, indissociável da política e outras relações de poder, além de construir uma prática nas aulas de Ciência que contribua com discursos menos homogeneizadores e mais interculturais, foi traçado um caminho de possibilidades que chamamos de CTS-ARTE.

\section{A estratégia didática}

Consideramos o surgimento do termo CTS-ARTE como um híbrido entre as fronteiras da abordagem CTS e os limites da abordagem da Educação em Artes - limites existentes em aulas de Ciências - e esse trabalho na fronteira da cultura exige o encontro com um novo (Figura 1).

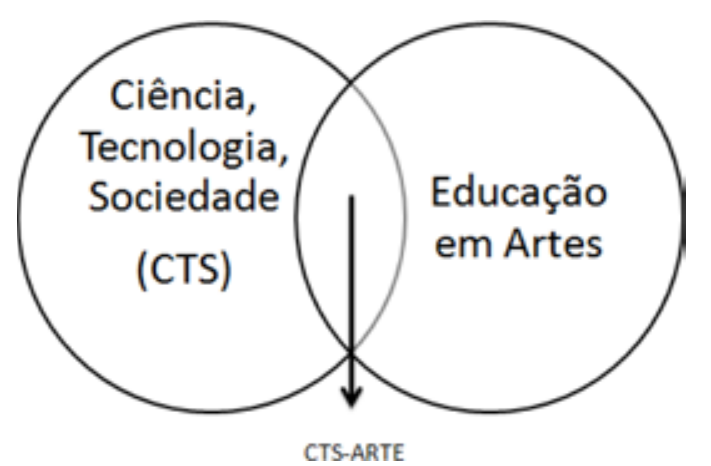

Figura 1: CTS-ARTE como Híbrido entre CTS e Educação em Artes

Essa abordagem CTS-ARTE busca transcender à utilização da Arte nas aulas de ciência apenas como uma motivação proporcionada pelo trabalho artístico. Utilizamos a Arte na intenção de proporcionar discussões de caráter político, social, ambiental, ideológico, afim de permitir, também, o diálogo entre as diferentes culturas.

A estratégia CTS-ARTE busca tanto partir do cotidiano do aluno, por compreender que é necessário valorizar questões nele inseridos, como introduzir elementos de Belas Artes ou da Arte Popular, para que o estudante vá além de seu próprio cotidiano e conheça outros tipos de produção de conhecimento e expressão humana. Dessa forma, argumentamos que o termo CTS-ARTE é fundamental para a construção dos sentidos que conduzem à prática elaborada em nosso contexto de trabalho, além de permitir que essa prática adquira novos sentidos em outros grupos que busquem fazer um trabalho semelhante ou apoderem-se dessa estratégia didática.

A sequência didática que temos buscado inspira-se basicamente na proposta de Aikenhead (1994), na qual se inicia uma prática CTS a partir da discussão de uma questão social, discute-se a tecnologia, a Ciência e retor- 
na-se à questão social. Porém, para nós, a apresentação de um problema ou questão de caráter social é feita através da relação Arte + Sociedade (BAY, 2006) (Figura 2). Essa relação é possível tendo em vista que Bay (2006) nos mostra a possibilidade de relacionar Arte por via de uma interpretação social, através do sentido proposto por Marx, como a Arte sendo capaz de expressar a luta de classes, por ser ela um reflexo social, e por Foucault, como capaz de expressar uma relação entre o dito e o não dito, e as relações de poder. Ambas nos interessam em uma situação educacional que possa educar na vida e para a vida em sociedade (IMBERNÓN, 2000). Assim, a estratégia adotada no projeto pedagógico tem sido proposta a partir do já estabelecido curricularmente. Algumas etapas indicadas pela seta compõem nossa estratégia: 1) é escolhido um tema social a partir de uma relação com a Arte; 2) uma tecnologia é introduzida; 3) estuda-se a ciência e sua relação com tecnologia e sociedade; 4) a questão social é rediscutida; 5) é proposto aos estudantes que elaborem um produto final científico-artístico.

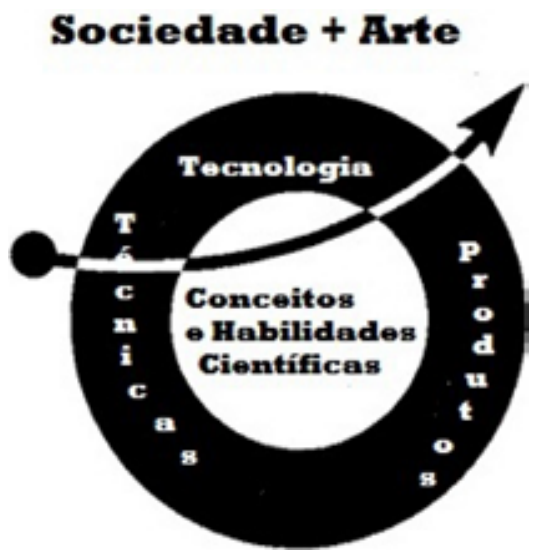

Figura 2. Proposta CTS-Arte adaptada de Aikenhead (1994).

A relação Arte e Sociedade é uma via de mão dupla e não devemos apenas compreendê-la pelo aspecto social, descartando as individualidades e singularidades da criação artística. Em nossa proposta, buscamos expressões artísticas que permitam abordar a questão social com a liberdade de uma estratégia didática e não como uma interpretação do que o artista quis expressar realmente. Consideramos a Obra de Arte como obra aberta (ECO, 2010), havendo, assim, múltiplas possibilidades de interpretações que dependerão do intérprete dessa maneira "Aberta” e de como ela é utilizada para mostrar uma relação existente entre a obra e o intérprete. A obra não depende apenas dos sentidos atribuídos pelo autor, isso porque cada observador terá uma interpretação diferente que irá variar com sua sensibilidade condicionada, sua cultura, gostos, propensões, ou seja, sua forma individual, o que faz com que a obra possa ser vista e compreendida segundo múltiplas perspectivas. Essa abertura nos permite a interpretação social de uma obra de Arte sem colocar em menor grau as singularidades da criação, mas valorizando nossos objetivos educacionais.

A última etapa do trabalho é a produção, pelos estudantes, de um produto com característica científico-artística - podendo ser qualquer tipo de manifestação artística, como pintura, música, literatura, teatro. O produto será fruto das identidades daqueles que o produziram, e a abertura para diversas possibilidades de construção permitirá que haja a expressão e significação de crenças, valores e de suas posições culturais naquele dado instante.

\section{O tema: Estações de tratamento de esgoto}

A construção do conhecimento sobre o tratamento de esgoto torna-se relevante em um ensino que visa à formação de cidadãos capazes de interpretar o mundo que os cerca, ao agir com crítica e consciência ambiental. Segundo Schnetzler e Santos (2003), em sua pesquisa com alguns dos principais Educadores em Química do Brasil, 83\% citaram a Química Ambiental como um “Tema químico social” por propiciar: i) contextualização 
do conhecimento químico com o cotidiano do aluno e ii) desenvolvimento de habilidades básicas relativas à cidadania.

A relevância social, política e cientifica da existência das estações de tratamento de esgoto se inicia no instante em que a sociedade em geral passa a se preocupar com a qualidade da água. Conceito este que é muito amplo, devido as suas propriedades de solvente, a capacidade de armazenar e transportar matéria orgânica e inorgânica.

Como descrito por Von Sperling, em Introdução à qualidade das águas e ao tratamento de esgoto, a qualidade da água é resultante de fenômenos naturais e antrópicos, ou seja, da atuação do homem.

A utilização de estações de tratamento de esgoto surge para minimizar a interferência humana na qualidade da água, pois as mesmas irão tratar despejos domésticos e industriais. Despejos esses que modificam as características físicas, químicas e biológicas, interferindo no parâmetro de qualidade da água.

Segundo BEZERRA e REIS (2009), desde muito tempo o homem tinha a ideia de que os resíduos sólidos e efluentes gerados tinham uma ligação com mal-estar, no entanto, só havia preocupação em afastar esses resíduos dos locais de moradia humana, tendo como prática a transferência dos problemas para lugares "distantes", lançando lixo e esgoto nos rios, lagos, mares e florestas sem qualquer tratamento prévio. As estações de tratamento de esgoto estão diretamente ligadas à preservação do meio ambiente, sendo de grande relevância o seu estudo.

\section{A arte escolhida}

Neste trabalho, a obra escolhida foi o cordel “A falta d'água no mundo”, de João Batista Melo, poeta popular que nasceu em Itabaianinha, no estado de Sergipe. No ano de 1938, mudou-se para Niterói, no Rio de Janeiro, e é atual membro da Academia Brasileira de Literatura de Cordel (ABLC) e da Academia de Letras da Região Oceânica de Niterói (ALRON), expondo e vendendo suas obras em barraca de uma feira no Campo de São Bento, parque popular de Niterói. Com o folheto “A falta d'água no mundo” foi homenageado pela ONU em uma carta escrita por Giancarlo Summa, diretor da United Nations Information Center (OLIVEIRA; QUEIROZ, 2013). O cordel permitiria fazer uma abordagem de Educação Ambiental Crítica, caracterizada por Lima (2011) como uma compreensão multidimensional da questão ambiental; defesa do amplo desenvolvimento das liberdades e possibilidades humanas e não humanas; atitude crítica diante dos desafios da crise civilizatória; uma publicização da problemática socioambiental; uma associação de argumentos técnico-científicos à orientação ética do conhecimento; um entendimento da democracia como pré-requisito para a construção de uma sustentabilidade plural; a certeza na participação social como indispensável à democracia; cuidado em estimular diálogo e a complementariedade entre as ciências; uma vocação transformadora dos valores e das práticas contrárias ao bem-estar público.

Essa abordagem converge com os objetivos CTS segundo Santos et. al. (2010) e é considerada importante para um processo chamado "ambientalização" que, para os autores, seria um movimento de busca por uma mudança de valores nas relações entre os seres humanos e com o ambiente que interagem. A partir desse eixo, os autores Oliveira e Queiroz (2013b) mostram que é possível estabelecer uma relação entre Educação Ambiental Crítica, importante à prática CTS, e as Obras de João Batista Melo.

Dessa forma, o Cordel “A falta d'água no mundo” foi escolhido para ser trabalhado em sala de aula, uma vez que acreditava-se que possibilitaria a formação de um estudante mais crítico e politizado que buscasse refletir sobre questões sociocientíficas como as que cercam os temas relativos à água.

Outro ponto a ser destacado é a possibilidade de contribuir para que estudantes conheçam um pouco da cultura do nordeste, diminuindo a distância entre a cultura científica e humanística. E apresentando-os o olhar do outro que, nesse caso, é o imigrante nordestino. SILVA et. al. (2010) nos mostram a Literatura de Cordel como 
uma poesia narrativa de caráter popular, que dissemina as raízes e a cultura nordestinas e, ao mesmo tempo, retrata a ficção e a realidade dessa região. A leitura passa a ser compreendida a partir de relações cognitivas, social, cultural e política, ou seja, uma relação direta com a realidade do aluno.

O cordel, como arte explorada durante o trabalho, nos trouxe todas essas "exigências" e, além de ser uma literatura bastante conhecida e divulgada no nordeste do país, também possui fácil acesso e preço relativamente acessível.

\section{OBJETIVOS}

O objetivo geral deste artigo é investigar se, através da Arte Final, os estudantes expressaram as discussões de cada uma das aulas da estratégia CTS-ARTE envolvida. Como objetivos específicos, incluímos a reflexão sobre como foi o aprendizado do conteúdo de química separação de misturas. Também queremos compreender como ocorreu a relação dos estudantes com o tema estação de tratamento de esgoto, suas implicações sociais e ambientais e, por fim, presentar a literatura de cordel e despertar nos alunos uma maior compreensão sobre a cultura nordestina, além de ampliar o entendimento crítico sobre o tema discutido.

\section{METODOLOGIA}

A metodologia pode ser divida em i) metodologia de elaboração das aulas, referindo-se ao processo de pedagogização do conteúdo de métodos e separações de misturas a partir da estratégia didática CTS-ARTE; ii) metodologia da pesquisa, referindo-se aos procedimentos de coleta e análise de dados da pesquisa.

\section{Metodologia de elaboração das aulas}

A elaboração do planejamento iniciou-se a partir do preenchimento de uma tabela para a construção do projeto. O guia buscava indagar o professor sobre 1) quais questões seriam discutidas sobre as relações CTS ; 2) quais conteúdos serão abordados; 3) Qual ambiente educacional, descrição da sala de aula, dos alunos, quanto a faixa etária e número; 4) quanto tempo será necessário para a abordagem; 5) Quais elementos da sociedade serão discutidos e qual arte conduzirá a essas discussões; 6) Quais materiais serão necessários (vídeos e imagens, etc.); 7) Qual elemento de tecnologia será discutido e como ele será relacionado à ciência; 8) Como será feita a nova discussão da questão social (utilizando do debate, controvérsias...); 9) Qual será a arte dos alunos.

Assim, decidiu-se que seriam discutidas as 1) relações existentes entre a tecnologia - estação de tratamento de esgoto - e a sociedade; 2) como conteúdo - métodos e separações de misturas; 3) como ambiente educacional - uma turma de $9^{\circ}$ ano com 15 estudantes; 4) utilizando-se 8 aulas de 50 minutos; 5) A arte utilizada seria o cordel “A falta d'água no mundo" e abordar-se-ia a importância da estação das estações de esgoto na sociedade; 6) seriam utilizados vídeos sobre ETE, textos sobre métodos e separações de misturas e uma notícia de um jornal regional; 7) os estudantes seriam indagados sobre quais métodos de separação estariam presentes nas ETE; 7) A discussão da sociedade seria feita a partir de uma roda de discussões sobre uma notícia divulgada em um jornal local; 8) A arte dos estudantes seria livre. No intuito de realizar uma prática baseada nesses princípios foi buscouse: - pesquisa bibliográfica utilizando livros didáticos, artigos de Ensino de Ciências, de Química Ambiental e de sítios da internet; análise de vídeos existentes na internet para serem utilizados durante as aulas; adaptação de textos sobre fatos cotidianos relacionados ao conteúdo - esses textos foram disponibilizados aos estudantes para leitura, informação, e busca por mais conhecimento sobre o tema; execução metodologia CTS-ARTE; Aplicação de um teste, requisito obrigatório do colégio no qual a prática foi elaborada. 


\section{Metodologia da Pesquisa}

É possível enquadrar nossa pesquisa como Qualitativa. Segundo Bogdan e Biklen (1994), essa categoria de pesquisa possui como fonte direta dos dados o ambiente natural, sendo o investigador o instrumento principal; é, também, descritiva, ou seja, os dados são compostos por entrevistas, notas de campo, fotografias, vídeos, entre outros, e cada detalhe não pode ser deixado de lado por construir parte fundamental para uma melhor compreensão do objeto investigado; os investigadores se interessam mais pelo processo do que pelo resultado buscam-se os “comos” e não apenas um resultado final; dá importância ao significado, ou seja, preocupa-se em compreender como as pessoas utilizarão algo para dar sentido em sua vida.

Em nossa investigação, foi utilizada, como corpus da pesquisa, a arte final desenvolvida pelos estudantes. Assim, o material textual foi analisado segundo a estratégia de análise de conteúdo (MORAES, 1999) - referencial que visa descrever e interpretar conteúdos retirados de diversas classes, buscando a participação da teoria e da prática no campo das investigações sociais.

Após as aulas, as artes dos estudantes foram transcritas, tanto os textos quanto o vídeo gravado. Em seguida, foram feitas as seguintes etapas: 1 - Preparação das informações; $\mathrm{O}$ texto dos alunos foi catalogado de acordo com os grupos para a produção da arte final. Sendo assim, utilizou-se os códigos G1, G2, G2, G4 e G5. 2 - Unitarização ou transformação do conteúdo em unidades; os dados foram submetidos ao processo de unitarização, ou seja, foram buscados elementos de unidade, que remetessem às aulas dadas anteriormente, e em seguida foram estabelecidos códigos, de forma que cada trecho selecionado recebeu uma letra, em ordem alfabética para clarificar a posição na qual o trecho aparece no texto. Ex: G1a, G1b, G1c... G2a, G2b... G3a, G3b... Por fim, foram definidos Episódios que agruparam as determinadas unidades. 3 - Categorização ou classificação das unidades em categorias; após a classificação em Episódios, foi feito o agrupamento em categorias, ou seja, os dados foram separados de acordo com algo em comum entre eles. Esse processo de categorização foi feito $a$ priori, uma vez que se buscou estabelecer, como foi expresso, na arte, os momentos e discussões das aulas anteriores. 4 - Descrição; Após elencar episódios e categorias, foram elaborados pequenos textos que introduzem as reflexões sobre cada uma das unidades analisadas. 5 - Interpretação: nessa etapa buscaram-se interpretações, ou seja, ir além da descrição da etapa anterior e buscar uma compreensão mais aguçada sobre o objeto de análise.

\section{Descrição do ambiente escolar}

Escola particular de médio porte, localizada na cidade de São Gonçalo, região metropolitana do estado do Rio de Janeiro. Cidade esta que não possui tratamento adequado de rejeitos domésticos e industriais e que está locada às margens da Baía de Guanabara. A turma onde a pesquisa foi desenvolvida era composta por 15 alunos, com idade média de 14 anos, do nono ano do ensino fundamental, antiga oitava séria. Em sua maioria meninas. A professora descrita a seguir será chamada de Ana para manter sua identidade em sigilo.

\section{ANÁLISE DOS RESULTADOS}

É imprescindível ao trabalho fazer uma detalhada contextualização do cenário do colégio e de todas as aulas para que, no momento seguinte, se estabeleçam os Episódios e Categorias. Dessa forma, a análise do trabalho será divida em duas partes, sendo a primeira a descrição do desenvolvimento das aulas. E segunda a discussão dos episódios e categorias da arte desenvolvida pelos alunos.

\section{A prática - Uma descrição a partir da tomada de notas de um pesquisador presente em sala}

Dia "zero" e primeiro dia: no dia anterior ao recebimento de Ana, o professor da turma apresentou para os alunos a obra "A importância do cordel na comunicação", de João Batista Melo, mesmo autor do cordel que seria utilizado em breve. O momento seguinte foi o primeiro dia da professora Ana e, ao dar início à aula - após 
apresentações e formalismos - ela perguntou como os alunos preferiam que o cordel fosse lido e eles se expressaram afirmando que o interessante seria lerem juntos. Cada estudante ficou responsável pela leitura de uma folha - Nesse momento, era perceptível uma concentração e participação dos estudantes na aula. Esse fato é, inicialmente, função do estranhamento que os estudantes sentem ao se depararem com um novo professor, porém, essa tensão foi diluída com o tempo - Após a leitura do cordel, que durou aproximadamente 15 minutos, Ana fez a ligação entre a Arte e a Sociedade ao perguntar se há tratamento de esgoto na cidade. Muitos participaram falando ao mesmo tempo e levantando questões como a sujeira da Baía de Guanabara. A sala ficou caótica, mas logo ela conseguiu organizar a sequência das falas. Ana comentou sobre os recursos financeiros necessários para construir uma Estação de Tratamento de Esgotos (ETE) e uma aluna rapidamente ironizou a atual prefeitura da cidade que "Só sabe fazer praça" e não se preocupa com questões básicas como o lixo e o tratamento de esgoto. Outro estudante comentou a questão dos impostos e afirmou que os impostos pagos são para que obras como essa sejam feitas. Já um terceiro aluno comentou como os hospitais da cidade estavam degradados e novamente apareceu a fala de um aluno que disse "A prefeita só sabe fazer praça".

Ana interrompeu o debate e a turma foi dividida em dois grupos. Enquanto um grupo assistia aos vídeos, o outro pegou um material que foi preparado por ela com o conteúdo de ETE e separações de mistura. Um grupo ficou com oito alunos e outro grupo com sete alunos. No total, foram dois vídeos selecionados previamente, sendo um deles de autoria de uma empresa de ETE que mostrava detalhadamente os processos por ela utilizados, o outro era do Jornal Nacional e mostrava uma notícia que relacionava ETE e uma cidade em questão, cada vídeo com aproximadamente cinco minutos. No grupo que assistiu primeiro ao vídeo, a professora pediu para os alunos buscarem no texto métodos de separação de misturas que apareciam no que foi visto; no grupo que leu primeiro o texto, ela pediu que buscassem nos vídeos métodos de separação que apareciam no texto. Com isso, poderiam relacionar o material preparado com a tecnologia de estação de tratamento de esgoto após uma abordagem crítica sobre a cidade. No bate papo sobre o conteúdo, ela comentou em um dos grupos sobre processos anaeróbicos e aeróbicos, falando sobre a presença e falta de oxigênio, mas sem aprofundar o assunto.

Após os vídeos e a leitura, Ana juntou os dois grupos e perguntou qual era o método presente no vídeo. Uma aluna respondeu: filtração; Ana comentou que há dois tipos de filtração para resíduos diferentes; falou a diferença entre lixão e aterro sanitário e perguntou qual o outro método. Um aluno respondeu: decantação. Ela então explicou brevemente a decantação e retomou uma pergunta feita durante a exibição do vídeo em um dos grupos. “A água após tratada pode ser consumida?” Essa pergunta foi respondida com um não, alertando que aqui no Brasil não há o tipo de tratamento que transforma a água usada em potável, mas que a ETE faz com que a água volte para o meio ambiente mais limpa. Ana disse algumas vezes que tudo é um ciclo. "Adubamos o solo com nossas fezes, o boi come o pasto e comemos o boi. Daí, produzimos fezes para adubar o solo. Somos parte desse ambiente”. Também comentou sobre tratamento de água dizendo que, ao sair do tratamento, é potável, mas, ao passar por todo caminho até chegar à nossa casa, há tubulação antiga, furos e sujeira, o que faz com que a água não seja boa para consumo. É possível perceber que em muitos momentos Ana retomou frases do cordel para dar ênfase ao que estava sendo dito, comentando também sobre a obra do Complexo Petroquímico do Rio de Janeiro (COMPERJ) e a necessidade de fazer tubulações que irão da CEDAE no Rio de Janeiro até uma cidade próxima. Também falou sobre questões políticas e sociais, como o preço do IPTU referente à área onde se mora e a relação com a proximidade do mar, mostrando relações de poder e a perda financeira de dinheiro proveniente de turismo. A professora pediu, também, que lessem o material de apoio sobre "Separação de misturas" e a aula foi encerrada com a fala do que será abordado na aula seguinte.

Segundo dia: Ana iniciou a aula perguntando se haviam lido o material de apoio. Os estudantes disseram que sim e que não tinham dúvidas sobre o que leram. Ela passou o segundo material de apoio, que é um texto sobre ETE produzido por ela e uma lista com cinco exercícios que necessitariam tanto do material da última aula, sobre separação de misturas, quanto desse texto da aula de hoje. Os exercícios foram retirados de questões do vestibular, o que causou um estranhamento nos estudantes que não tinham se deparado ainda com questões desse tipo. Ela caminhou pela sala tirando dúvidas pontuais. Nesse momento, os alunos permaneceram agitados, mas muito participantes. Pela primeira vez, Ana sentiu a necessidade de ir ao quadro, já que um estudante perguntou sobre decantação, e fez um desenho falando sobre a densidade da água e do óleo e como é possível separá-los. 
Acrescentou que é um processo manual e que há uma pessoa controlando a torneira. A todo o momento ela buscou os conhecimentos de ETE trabalhados na aula anterior para facilitar e relacionar ao conteúdo da aula. O tempo para exercícios acabou e ela começou a corrigi-los fazendo uso do quadro. Perguntou para todos o que marcaram e aos poucos foram surgindo as respostas, havendo uma discussão de todas as questões, item por item, para justificar cada apontamento. O quadro foi usado novamente para explicar a destilação. Ela utilizou-se de um desenho para mostrar o processo e disse que a água se separa da acetona porque as duas substâncias apresentam uma diferença de ponto de ebulição. Já a mesma questão (1) apresenta um item sobre fusão fracionada que ela não havia explicado, pedindo para os alunos não o fazerem, e explicando, então, o processo. Isso se repetiu com todas as questões.

O momento seguinte foi o momento do debate. Ana separou uma reportagem e fez uma cópia e distribuiu para todos os alunos. Pediu para lerem e, em seguida, convocou todos os estudantes para a discussão. Organizou a turma em círculo e passou as regras da discussão. Ana pediu uma leitura em voz alta que é feita por dois estudantes, dando início, em seguida, à discussão. Um total de aproximadamente 30 minutos de discussão foi gravado em áudio e as falas foram posteriormente transcritas. Entre 15 estudantes presentes no debate, houve a participação ativa de nove. Os outros seis se calaram. No total de dez vozes, contando com a professora, no debate foram levantadas questões sobre política E1: "Eu acho que eles tão fazendo isso pra obter voto. Tão fazendo isso por causa das eleições. Se você for buscar antes e for ver que o que eles tudo prometem antes"; Administração pública E2: "Ah é, e eles vão tirar dinheiro de onde pra fazer? Vão tirar do bolso deles? E a gente paga imposto"; Benefícios que a ETE pode trazer para a cidade E3: "O banho na praia? Gerar turismo pra cidade? Conseguindo mais dinheiro dá pra se investir mais”. Entre outras questões. Ao final foram divididos os grupos para a elaboração de um produto científico artístico. Foi pedido que os trabalhos mostrassem o conteúdo e o tema abordado através de um cordel, peça de teatro, telejornal encenado, pintura ou escultura. Podendo ser mais de um tipo de produção ao mesmo tempo, Ana reafirmou que esse trabalho valeria parte dos pontos do bimestre.

Terceiro dia: nesse momento ocorreu a apresentação dos trabalhos pelos estudantes, sendo que apenas um faltou. Iniciou-se a apresentação e ela ficou de espectadora. Quatro grupos escolheram cordéis que foram intitulados "Atenção, povo! Vamos acordar!”; "Nosso Mundo”; “A falta de água” e, “Cordel sobre a água”. Um grupo fez a encenação de um telejornal que consistia no diálogo entre uma apresentadora, uma entrevistadora e a candidata à prefeita da cidade. Durante a prática, foi feito um pedido pela coordenação: uma avaliação "tradicional” a ser feita no quarto dia. Durante o planejamento, esperava-se utilizar quatro aulas, mas foram utilizadas três. Dessa forma, a última aula foi o teste

Quarto dia: No último dia, a turma foi separada em três fileiras para aplicar o teste. Ana se despediu dos alunos e disse que era a última vez que ela iria esse ano à escola, agradecendo o carinho. Após aplicar o teste, foi embora.

\section{Análise da produção dos estudantes.}

A análise de conteúdo foi dividida previamente em três Episódios, denominados respectivamente: Discussões apresentadas na primeira aula; Conteúdos científicos; Discussões elaboradas durante o debate. Categorias foram nomeadas previamente da seguinte maneira:

\section{- Episódio 1: Discussões apresentadas na primeira aula.}

- Categoria 1: conteúdo dos vídeos

- Categoria 2: conteúdo do cordel "A falta d'água no mundo”.

\section{- Episódio 2: Conteúdo científicos}

- Categoria 1: Aspectos sobre a água 


\section{- Episódio 3: Discussões elaboradas durante o debate}

- $\quad$ Categoria 1: percepções políticas

- $\quad$ Categoria 2: participação popular

O Episódio I, intitulado “Discussões apresentadas na primeira aula.” remete ao desenvolvimento das duas primeiras atividades aplicadas aos alunos, ou seja, a leitura do cordel e a visualização dos vídeos acompanhados de alguns esclarecimentos sobre estação de tratamento de esgoto. Dessa maneira, separamos o episodio I em duas categorias. A primeira, “denominada conteúdo dos vídeos” encontramos evidencias claras dos vídeos na arte dos alunos. Já a segunda categoria, denominada “conteúdo do cordel “A falta d’água no mundo”, foi utilizado para agrupar trechos que possuíam influencia da arte lida durante a primeira aula”.

As falas dos alunos que se relacionam com a Estação de Tratamento de Esgoto, em sua maioria estão atreladas ao desenvolvimento político da cidade, pois a cobrança dá falta de uma estação de tratamento de esgoto é diretamente ligada à falta de interesse público na construção da mesma, como podemos exemplificar com esta fala: G2d “O esgoto irá entupir/ E nenhum tratamento irá surgir/ Estações de tratamento/ O governo deve criar/ Mas quem disse que eles/ Querem nos ajudar?” Mesmo quando identificamos uma preocupação sócio-ambiental, está atrelada às falas e a cobrança política aos governantes da cidade em questão; tal observação é facilmente vista no seguinte trecho: G5a“Repórter: Bom dia prefeita, qual é o propósito de criar a estação de tratamento? Prefeita: A proposta é menos poluição nas ruas e maior proposta de emprego para a população... entendeu? Menos valões pelas ruas, que causam mal odores porque temos muita reclamação sobre isso... Sobre as enchentes, também. O POVO MERECE UM LUGAR MELHOR! SÃO GONÇALO MAIS DIGNO (PALMAS).”

Nessa categoria, ficou evidente que os vídeos que mostravam a parte mais técnica das Estações de Tratamento de esgoto não apareceram na arte final, já os vídeos que mostravam uma preocupação ambiental e política marcaram os textos dos estudantes.

Na segunda categoria pode-se observar a ligação direta entre o cordel “A falta d'água no mundo” e as implicações ambientais quanto a todos os tipos de poluição ambiental. Tal descrição é perfeitamente empregada quando lemos a seguinte passagem: G1a”Hoje viemos falar sobre/ um problema prejudicial/ Não só para mim, mas para todo pessoal/ Vem causando muitas doenças/ e até muitas enchentes/Como podemos acabar com os poluentes?" No entanto, o que melhor retrata o desenvolvimento da discussão em que o cordel foi o ponto inicial são as falas onde encontramos a preocupação com a preservação do líquido precioso de que estávamos falando, essa percepção surge com a existência de muitos trechos encontrados nos trabalhos dos estudantes e que podem ser representados pelos trechos a seguir: G3a“Vou falar aqui de um líquido especial/ que no nosso planeta a existência é fundamental/seres humanos e animais sem ela a vida é incapaz./ água que faz tudo crescer./ A água que nos permite plantar e colher/ um item de mil utilidades/tão grande sua força e capacidade./Habita os lagos, mares e oceanos/ até mesmo os animais e seres humanos/ tão grande tua importância é/ criada por Deus, em quem tenho fé." “G4a-É a água um grande bem/ Para a vida essencial/ É preciso que se faça/ Dela uso racional/ Preservando as gerações/ Futuras de um grande mal/ Por ser um bem precioso/Deve ser bem preservado/ Vida sem água não existe/ É preciso ter cuidado/ Só a água mata a sede/Ao demais é descartado/Entre ela e nossa vida/Há forte vinculação/ Ao utilizar a água/ É preciso atenção/ Evitar o desperdício/Virou mais que obrigação/Sendo o bem mais precioso/ O chamado Outro Azul/Vida sem ela não há/ Seja na seca ou na cheia/ No Brasil sobra no Norte/ porém já falta no sul”.

Esse retorno foi de grande valor, pois o amadurecimento dos alunos quanto à necessidade de preservação do meio em que estão inseridos, seja preservando a água ou cobrando a existência de tratamento de esgoto na cidade onde os mesmos residem, é de extrema importância tanto para o objetivo do trabalho que foi desenvolvido, quanto para o crescimento pessoal de cada estudante e conseqüentemente de todos que convivem de forma direta ou indireta com ele. 
No episódio de número II, denominado Conteúdos científicos, destacamos momentos dos trabalhos desenvolvidos pelos alunos onde se encontram conceitos apresentados durante a aula sobre separação de misturas. Nesse episódio está dividido somente em uma categoria. Nela apresentamos o único fragmento dos materiais que obtivemos como resultado, em que encontramos o conteúdo químico estudado durante a prática pedagógica. Não podemos deixar de destacar que o assunto específico, separação de mistura, foi pouco explorado pelos alunos. E que em nenhum momento localizamos nomes específicos de métodos de separação de mistura que foram estudados e avaliados por testes com os alunos. Para deixar mais clara a categoria, ela foi nomeada como "aspectos sobre a água". O trecho destacado remete a conceitos também citados durante a aula, por serem essenciais para o aprendizado do conteúdo em questão. Segue o trecho: "Seja doce ou salgada/ Seja cristalina ou não/ Incolor ou inodora/ Em qualquer situação/ Hidrogênio e Oxigênio/ Forma sua composição/ Em três estados se encontra/ Gelo, líquido, vapor/ Em todos há sua beleza/ Desde o pico de neve/ aos pingos d'água que caem do céu.

É importante destacar algumas questões nesse momento, o aspecto principal de conteúdo programático - métodos e separações de misturas - não foi abordado em nenhuma das artes finais, porém, o teste aplicado no último dia apresentou ótimos resultados. Acreditamos que os alunos tenham deixado de citar os conteúdos ou por questões estéticas ou por basearem suas artes na arte principal. O fato de o conteúdo científico não estar presente na arte não significou a falta de abordagem ou de aprendizagem.

\section{- Episódio 3: Discussões elaboradas durante o debate}

- Categoria 1: percepções políticas

- Categoria 2: participação popular

No terceiro e último Episódio, "Discussões elaboradas durante o debate" falaremos sobre situações que tiveram origem na discussão ocorrida durante o penúltimo momento do trabalho, o debate. Este Episódio foi dividido em duas categorias. A primeira, intitulada “percepções políticas”, será preenchida pela fala dos estudantes que mostraram opiniões políticas sobre os temas debatidos. A segunda, intitulada "participação popular”, mostra falas dos estudantes relacionadas à necessidade de participação popular. É preciso enfatizar que no momento da aplicação de todo o trabalho estávamos vivendo um momento eleitoral, ou seja, eleições para prefeitos e vereadores. E que o estado como um todo recebia ainda mais promessas por ter sido eleito para sediar grandes eventos esportivos. Para elucidar a:

Categoria I separamos dois trechos que exemplificam os dois momentos políticos vividos pelos alunos e moradores da cidade em que a escola reside. “G2g-Nas olimpíadas de 2016/ Tudo deve ficar bonito/ Para os turistas/ Que vão ver o Rio de Janeiro/ Como uma cidade bem vista/ Ninguém liga para a Parte pobre/ Só querem saber da Parte nobre/ Hospitais que são necessários/ Ninguém quer construir/ Mas para investir no maracanã/ Boas ideias parecem surgir/ Contanto que tudo / Esteja enfeitado por fora/ A parte de dentro Não importa/ De que adianta o governo/ Cuidar para que o estado Fique bonito/Se ele não tem/ Os recursos necessários/ Para ao menos cuidar de um distrito?" "G2e-Em época de eleições/ Milhões de promessas aparecem/ Quando elas não são cumpridas/ As coisas enlouquecem.”

Na categoria II, que faz referência a "participação popular", foi encontrada duas formas de reconhecimento dessa participação, uma como atitudes individuais, em que cada um precisa fazer sua parte para que o todo seja recompensado. E cobrança política de que em nosso país para que mudanças aconteçam é preciso que o povo vá à luta. Segue os parágrafos em destaque: "G1d-Já vimos que nós população vamos ter que por a mão na massa/ Pois aqui no Brasil não tem quem faça."; "G3c- Porque deixar para depois tomar providência/ se podemos mudar agora esse ato de demência?/ Algo precioso não deve ser desperdiçado/Sim, o máximo possível aproveitado/ água que não falta em lugar nenhum/ água que faz nosso planeta azul.”

A análise feita anteriormente teve como objetivo investigar como os estudantes expressam as discussões de cada uma das aulas da estratégia didática envolvida. 
Buscando uma visualização rápida, podemos apontar os principais constituintes da prática de CTS-Arte desenvolvida. Em um primeiro momento, leu- se a literatura de cordel “A FALTA D’ÁGUA NO MUNDO”, onde a obra busca demonstrar a importância da água e da não poluição da mesma. O tema "esgoto e estações de tratamento de esgoto" foi apresentado através de vídeos explicativos junto com material de apoio. O conteúdo de separação de misturas foi ministrado a partir de uma aula expositiva atrelada ao material de apoio e exercícios. O debate foi a partir da leitura de uma reportagem do jornal local sobre a construção de uma estação de tratamento de esgoto na cidade. Fechando, tivemos a apresentação da arte escolhida por eles para exporem suas opiniões e aprendizados. Essa sequência condiz com o apresentado por Oliveira e Queiroz (2013) na qual 1) é escolhido um tema social a partir de uma relação com a Arte; 2) uma tecnologia é introduzida; 3) estuda-se Ciência e sua relação com tecnologia e sociedade; 4) a questão social é rediscutida; 5) é proposto aos estudantes que elaborem um produto final científico-artístico.

O retorno do cordel é claro quando percebemos que a maioria dos grupos o escolheu como trabalho final na elaboração de cordéis e somente um grupo fez diferente, a execução de teatro "telejornal". Os temas de Esgoto e as estações de tratamento de esgoto foram reconhecidos facilmente, pois estiveram presentes em todos os trabalhos, porém, sempre com olhar sócio - ambiental e muito político, atribuímos isso ao momento político que a cidade estava vivendo, eleições para prefeitos e vereadores. Essa percepção mostra que o trabalho atingiu os objetivos de questionar os estudantes sobre a sua participação na política da cidade, além de introduzir um conteúdo a partir de sua relação com a tecnologia e a sociedade. Assim, acreditamos que o cenário de discussões mostrou-se de acordo com o que Lima (2011) considera como pertencente à Educação ambiental crítica uma vez que buscavam a solução da falta de ETE na cidade a partir de uma luta motivada pela conscientização da população na busca por um engajamento político e por uma maior participação popular.

No entanto, no que se refere ao tema "Métodos e Separações de misturas” não foi possível avaliá-lo pela Arte final. Nenhum dos estudantes teve a preocupação de falar sobre o conteúdo. Com isso, faz-se necessária uma pequena discussão sobre a avaliação tradicional obrigatória no colégio. Ocorreu a aplicação de um teste, no qual questões de múltipla escolha cobravam uma aprendizagem sobre métodos e separações de misturas. O resultado foi extremamente satisfatório uma vez que, com exceção de um dos alunos, todos acertaram mais de 50\% das questões, sendo 6,23 a média global. No momento da aplicação do teste foi reconhecido pelos alunos que na questão de número 3 havia erro, no momento da digitação, foi trocada a numeração correta, o que demonstrou maturidade dos alunos quanto ao conteúdo de ciências.

Mesmo tendo consciência da complexidade que é realizar avaliações, é possível afirmar que, nesse caso, uma aula que se utilizou da estratégia didática CTS-ARTE, além de contribuir para a formação do estudante como cidadão, atendeu aos conteúdos propostos de métodos e separações de misturas, referentes ao programa do $9^{\circ}$ ano da escola em questão.

\section{CONSIDERAÇÕES FINAIS}

Acreditamos ter alcançado grande parte dos objetivos propostos. Ficando claro através da arte que o entendimento da importância do processo de tratamento é de suma importância para suas vidas e o meio ambiente.

Durante os momentos de retorno da prática, quanto ao desenvolvimento dos alunos, ficou evidenciado a participação ativa dos estudantes. Todos que participaram ativamente das discussões expressaram na sua arte os pontos sociais, políticos e ambientais da cidade. O único grupo que abordou trechos de conteúdo científico foi formado por estudantes que não se expressaram durante o debate. Apesar de tamanha reclamação, quando divulgada a necessidade deles expressarem suas opiniões sobre todos os pontos discutidos - fosse por cordel ou outra forma de arte -, a maioria escolheu a literatura de cordel. Outro ponto surpreendente foi a tamanha criatividade e preocupação que tiveram em apresentar o trabalho. Devido ao momento de mudanças políticas na cidade, época de eleições, na sua maioria, os alunos tiveram falas durante o debate que tiveram como ponto de partida uma 
reportagem relacionada à falta de políticas publicas na cidade, não só ao meio ambiente, mas em todos os sentidos. O debate foi agitado e por muitas vezes foi necessário acalmar os ânimos, o que não é muito surpreendente, já que aquele momento dava voz a quem estava insatisfeito e indignado, mas quase nunca é ouvido e levado a sério pelos pais ou professores. Mesmo sabendo que são somente 15 alunos, foi perceptível uma evolução tanto em aspectos científicos, quanto em aspectos sociais e, principalmente, foram capazes de interligar temas que a primeira vista eram tão distintos e suas artes expressaram o tamanho do entendimento dos temas discutidos em sala de aula.

\section{REFERÊNCIAS BIBLIOGRÁFICAS}

ACEVEDO DÍAZ, J. A.; MANASSERO MASS, M. A. ; VASQUEZ ALONSO, A. Orientación CTS de la Alfabetización Científica y Tecnológica: un desafio educativo para el siglo XXI. In: Retos y perspectivas de la ensenãnza de las ciências desde el enfoque Ciencia-Tecnologia-Sociedad em los inicios del siglo XXI. Eds. Membiella, P. e Padilla, Y., Educación editora, p.7 -14, 2005.

ANDRADE, S. A; OLIVEIRA, R. D. V. L; NASCIMENTO, A. P. Esgoto: Tratamento, Sociedade e Meio Ambiente. Um debate para a formação do cidadão. SBQ, 2011.

AIKENHEAD, Glen. Educación Ciência-Tecnología-Sociedad (CTS): una buena idea como quiera que se le llame. Cidade do México, Educación química, v. 2, n. 16, p. 114-124, Abril, 2005.

AIKENHEAD, Glen. What is STS Science Teaching? In: SOLOMON, J., Aikenhead, G. STS education: international perspectives on reform. Teachers College Press, 1994. Disponível em: <http://www.usask.ca/ education/people/aikenhead/sts05.htm>. Acesso em: 07 jun. 2013.

AULER, Décio. Enfoque Ciência-Tecnologia-Sociedade: pressupostos para o contexto brasileiro. Ciência \& Ensino, Piracicaba, v. 1, n. especial, Novembro, 2007.

BAY, D. M. D. Arte e sociedade: pinceladas num tema insólito. Caderno de Pesquisa Interdisciplinar em Ciências Humanas, Florianópolis, n. 78, p. 2-18, Março, 2006.

BERNARDO, José Roberto da Rocha. A construção de estratégias para abordagem do tema energia a luz do enfoque Ciência-Tecnologia-Sociedade (CTS) junto a professores de Física do Ensino Médio. 2008. Tese (Doutorado em Ensino de Biociências e Saúde) - Instituto Oswaldo Cruz, IOC, Rio de Janeiro, RJ, Brasil, 2008.

BRASIL. Parâmetros Curriculares Nacionais do Ensino Médio. Ministério da Educação - Brasília: Ministério da Educação/Secretaria de Educação Médio e Tecnológica, 2000.

BRASIL. Parâmetros Curriculares Nacionais: Ciências Naturais. Ministério da educação. Secretaria de Educação Fundamental. Brasília: MEC/SEF. 1998. Disponível em: <http://portal.mec.gov.br/seb/arquivos/pdf/ ciencias.pdf>. Acesso em: 06 jun. 2013.

BRASIL.Parâmetros Curriculares Nacionais de $5^{a} a 8^{a}$ Séries: Arte. Secretaria de Educação Fundamental, Brasília: MEC/SEF, 1998.

BUSH, V. Science: The Endless Frontier - A Report to the President by Director of the Office of Scientific Research and Development, Washington, July, 1945.

CANDAU, V. M. Multiculturalismo e educação: desafios para a prática pedagógica. In: MOREIRA, Antônio Flávio; CANDAU, Vera Maria (Orgs.). Multiculturalismo: diferenças culturais e práticas pedagógicas. Petrópolis: Editora Vozes, 2010.

ECO, Umberto. Obra aberta. São Paulo: Editora Perspectiva, 2010. 284p. 
LIMA, G. F. da Costa. Crise ambiental, educação e cidadania: os desafios da sustentabilidade emancipatória. In Educação Ambiental repensando o espaço da cidadania. Loureiro, C. F.; São Paulo, Editora Cortês, 2011.

MORAES, Roque. Análise de conteúdo. Revista Educação, Porto Alegre, v. 22, n. 37, p. 7-32, 1999.

MORIN, E. A cabeça bem feita: repensar a reforma, reformar o pensamento. Rio de Janeiro: Bertrand Brasil, 2003. 128p.

MOREIRA, A. F.; CANDAU, V. N. Educação escolar e culturas. Revista Brasileira de Educação, n 23, p. 156168. Maio 2003.

OLIVEIRA, R. D. V. L.; QUEIROZ, G. R. P. C. Educação em Ciências e Direitos Humanos: reflexão-ação em/ para uma sociedade plural. Rio de Janeiro, Multifoco, 2013, 104p.

Poesia Ambiental de João Batista Melo: Poeta popular/ que tem muito a ensinar/ veio do sertão ao rio/ pra sua cultura divulgar. Sergipe, Scientia Plena, v. 9. p. 1-9. 2013 b.

PORTINARI, J. C. Mais do que um documento testemunhal - Candido Portinari: “Trabalho de amor e técnica”. In: Linhares, C. (Org.) Portinari e a cultura brasileira: um convite à educação a contrapelo. Niterói, RJ: Eduff, 2011.

RANCIÉRE, J. Entrevista. Ciência e Cultura, São Paulo, vol. 57, n.4, out/ Dez. 2005. Disponível em: <http:// cienciaecultura.bvs.br/scielo.php?pid=S0009-67252005000400011\&script=sci_arttext> Acesso em: 05 jun. 2013.

RICHTER, I. M. Arte-Educação Intercultural: pensando a realidade brasileira. In: INCLE, G. (Org.) Pedagogia da arte: entre-lugares da criação. Rio Grande do Sul, Editora UFRGS, 2010. 195p.

SANTOS, W. L. P.; MORTIMER, E. F. Tomada de decisão para ação social responsável no Ensino de Ciências. Ciência \& Educação, Baurú, v. 7, n. 1, p. 95-111, 2001.

SILVA, E. M. A.; ARAÚJO, C. M. Tendências e concepções do ensino de arte na educação escolar brasileira: um estudo a partir da trajetória histórica e sócio-epistemológica da arte/educação. In: reunião anual da ANPED, 30., 2007, Caxambu. Memórias da ANPED, 2007, p. 1 - 18.

SNOW, C. P. As duas culturas e uma segunda leitura. São Paulo: Edusp, 1995, 136p.

http://sec.sbq.org.br/cdrom/34ra/resumos/T0354-1.pdf

SCHNETZLER, R. P.; SANTOS, W. L. P. Educação em Química: compromisso com a cidadania. Rio Grande do Sul: Editora Unijuí. 2003, 144p.

http://www.oei.es/seminarioctsm/PDF_automatico/A1textocompleto.pdf

VON SPERLING, M. Princípios do Tratamento Biológico de Águas Residuárias: Introdução à Qualidade das Águas e ao Tratamento de Esgotos. 3. ed. Belo Horizonte: Departamento de Engenharia Sanitária e Ambiental da Universidade Federal de Minas Gerais, UFMG, v.1, 2005, 452 p. 
